\title{
Web-controlled optical amplifier for educational purpose
}

Frederic Capmas, Matthieu Boffety, Laurent Calixte, Guillaume Druart, Thierry Avignon, et al.

Frederic Capmas, Matthieu Boffety, Laurent Calixte, Guillaume Druart, Thierry Avignon, Nicolas Dubreuil, Marc Bondiou, "Web-controlled optical amplifier for educational purpose," Proc. SPIE 9664, Ninth International Topical Meeting on Education and Training in Optics and Photonics, 96641K (24 October 2005); doi: $10.1117 / 12.2207770$

Event: Ninth International Topical Meeting on Education and Training in Optics and Photonics, 2005, Marseille, France 


\title{
Ref ETOP086
}

\section{Web-controlled optical amplifier for educational purpose}

Frederic Capmas, Matthieu Boffety, Laurent Calixte, Guillaume Druart, Thierry Avignon, Nicolas Dubreuil and Marc Bondiou

\begin{abstract}
s
We describe an experiment that allows distant users to perform a labwork using Erbium Doped Fiber Amplifier (EDFA) in order to understand the basics physics and engineering involved. The EDFA and the measurement instrumentation are specially designed so as to allow for remote control through the web. The purpose of the project can then be distant learning for students from developing countries which cannot afford this kind of high-cost equipment.
\end{abstract}

OCIS codes: 060.0060 Fiber optics and optical communications, 060.2320 Fiber optics amplifiers and oscillators, 250.4480 Optical amplifiers

\section{Introduction}

\section{Summary}

Optical amplifiers are widely used and key devices in optical fiber communications. Our labwork experiment uses an EDFA presented as a "planar kit" including all suitable devices (pump and signal laser diodes, EDFA's fiber components including optical switches) arranged on a simple wood-slab, beside 2 laser controllers and an optical spectrum analyzer (OSA).

Locally or remotely, students set optical configurations so as to perform usual characterization of an EDFA using the optical switches to route and monitor pump, input and output signal towards the OSA. They can measure the pump level, the amplified spontaneous emission (ASE), the optical gain and gain behavior (saturation with respect to pump level and signal level, non uniformity of the gain with respect to wavelength, noise factor, etc.).

\section{Experiment}

2.1 Set-up
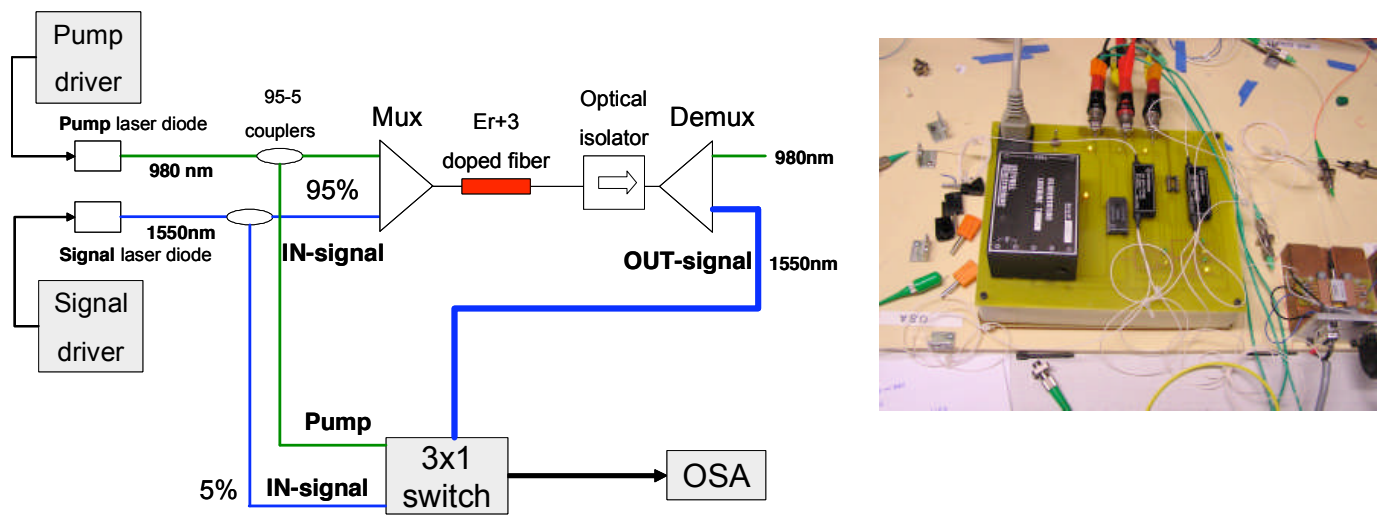

Fig. 1. Experimental set-up (right: detail).

Fig. 1 shows the set-up of the experiment. The laser pump and signal laser diodes are commercial-type butterfly packaged mounted with electrical interfacing for temperature and drive-current control from 2 laser ILX Lightwave controllers. Multiplexer (Mux), demutiplexer 
(Demux), 95-5 couplers and $\mathrm{Er}+3$ are on-the-shelf connectorized fiber components. A 4 ports (3 to 1) fibered optical switch routes any of the inputs towards the OSA (Anritsu). A National Instrument GPIB card allows for parallel control of the 2 laser drivers, and OSA setting and acquisition. National Instrument DACQ card allows for 3x1 switch control (special need for digital 5V-10 mA output voltage to actuate each individual switch part of the $3 \times 1$ switch).

\subsection{Laser diodes control}

Driving the current-source and temperature of the pump and signal laser diodes is managed through a Labview virtual instrument $(\mathrm{VI})$ that offers relevant controls in compliance with manufacturer specifications of the laser diodes (current and temperature range). Front-panel interface (see fig. 2 bottom left) is designed so as to offer non-expert user to easily switch on (or off) and adjust operating points that set the optical power of the sources (and fine tuning of the signal wavelength).

\subsection{Data acquisition control}

Each setting of the $3 \times 1$ switch corresponds to a typical setting (center wavelength, span, reference level, resolution bandwidth) of the OSA configuration for each input (pump, IN signal, OUT signal). A second VI (see front panels on fig.2 top) offers 3 different menus: "OSA setting", then "acquire" (acquisition and display of the spectrum of each input) and finally "results" (extraction from spectra of peak wavelength, peak intensity, noise level (ASE), then derives gain, NF, etc.).
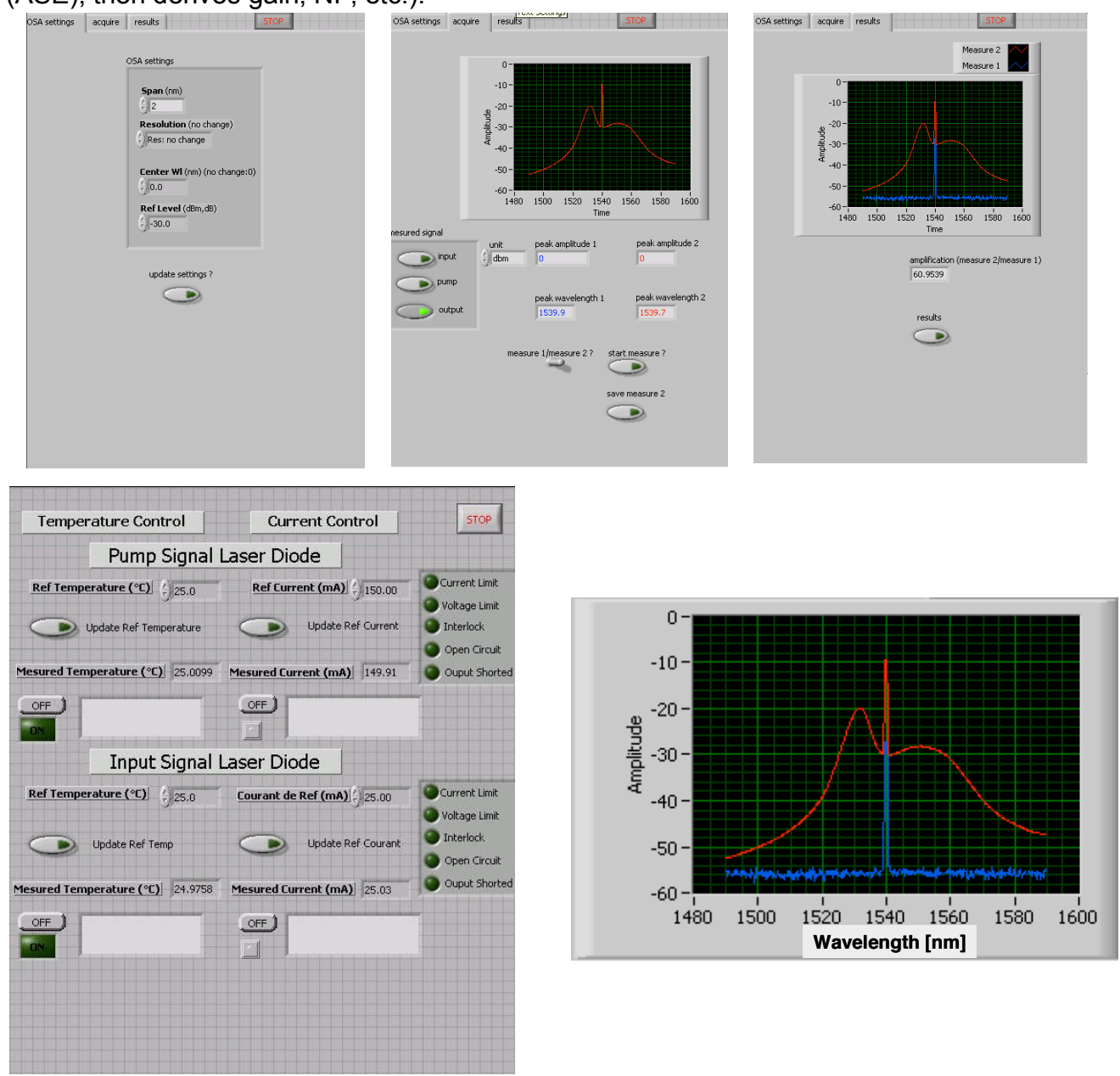

Fig. 2. VI front panels of the OSA (top) and of the laser diodes (bottom left) ; zoom on results (bottom right) 
New versions of Labview (7.0 or more) are rather easy to implement between two computers (one affected to the experiment and the other for the labwork) connected through local or extended network. In particular, of course, the second computer doesn't have to be installed with Labview.

In conclusion, we hope that this already well-known concept of web-controlled systems (robotics, etc.) applied to the field of education in optics and photonics will allow any distant user to become familiar with a real (though remote) EDFA which is not a simulation. The high cost required equipment might become available to one who could not afford it. Time sharing between local and distant users has to be organized, and, nevertheless, sponsorship from industry or international organizations has to be found to help for this kind of reach-out effort. 